\title{
Collecting sensitive information for a sexual health trial with young people: experiences of using electronic data collection and traditional paper methods
}

\author{
Lisa Maguire ${ }^{1,2^{*}}$, Aine Aventin $^{1}$, Dirk Schubotz ${ }^{1}$, Laura Dunne ${ }^{1}$, Maria Lohan ${ }^{1}$, Mike Clarke ${ }^{1}$
}

From 3rd International Clinical Trials Methodology Conference

Glasgow, UK. 16-17 November 2015

Electronic data collection for randomised trials is attractive as it can, in theory, provide great financial advantages by reducing fieldwork costs and data inputting time, as well as increasing the accuracy of responses over and above paper based methods. For trials involving young people, electronic methods provide other advantages such as the ability to adapt questions to meet the needs of young people of differing ages and abilities. Researchers have also suggested that young people prefer electronic methods over traditional ones and have found equal validity across both methods. This presentation will discuss issues relating to the collection of sensitive information from young people in Northern Ireland, using electronic and paper formats. We will draw on experience gained across several research studies that have collected data on sexual risks and behaviours, particularly in school-based research; including a recent trial on adolescent pregnancy. We will examine the feasibility, reliability and validity of data collected along with an evaluation of the cost implications and ease of using both methods (including the merging of the resulting datasets if both methods are offered). The views of the researchers and participants will also be reflected upon.

Authors' details

'Queen's University Belfast, Belfast, UK. 'University of Liverpool, Liverpool, UK.

Published: 16 November 2015

${ }^{1}$ Queen's University Belfast, Belfast, UK

Full list of author information is available at the end of the article
doi:10.1186/1745-6215-16-S2-P18

Cite this article as: Maguire et al:: Collecting sensitive information for a sexual health trial with young people: experiences of using electronic data collection and traditional paper methods. Trials 2015 16(Suppl 2): P18.
Submit your next manuscript to BioMed Central and take full advantage of:

- Convenient online submission

- Thorough peer review

- No space constraints or color figure charges

- Immediate publication on acceptance

- Inclusion in PubMed, CAS, Scopus and Google Scholar

- Research which is freely available for redistribution
() Biomed Central 